\title{
HIV/AIDS Treatment Failure and its Determinant Factors among First Line HAART Patients at Felege-Hiwot Referral Hospital, Bahir Dar, Northwest Ethiopia
}

\section{Bokretsion Gidey Brhane ${ }^{1 *}$, Endalkachew Nibret ${ }^{2}$ and Getachew Kahsu Abay ${ }^{3}$}

${ }^{1}$ Malaria and Other Neglected Tropical Disease Research Team, Ethiopian Public Health Institute (EPHI), Addis Ababa, Ethiopia

${ }^{2}$ Department of Biology, College of Science, Bahir Dar University, Bahir Dar, Ethiopia

${ }^{3}$ College of Medicine and Health Sciences (CMHS), Adigrat University, Adigart, Ethiopia

\begin{abstract}
Introduction: Highly active antiretroviral therapy (HAART) played a critical role in the medical management of HIV infected individuals by restoring the immune function and minimizes HIV related outcomes. But treatment failure minimized these advantages and leads to an increment of morbidity and mortality with poor quality of life in all HIV patients.

Objective: The aim at this study was to assess the prevalence of HIVIAIDS treatment failure and its determinants factors of patients on first line HAART at Felegehiwot Referral Hospital.

Methods: Cross sectional study was conducted on 421 participants who had started first line HAART during August 2016 to September 2016. Data were collected from patients' chart starting from ART commencement and face to face interview using structured questionnaire. CD4 T-cells from whole blood and viral load from separated plasma were analyzed according to protocols. The collected data were enter in to EPI info version 3.5.1 and transfer to and analyzed using SPSS packages version 20. Descriptive statistics, odds ratio, positive and negative predictive values, life table, receiver operating characteristics curves, bi-variate and multiple logistic regression were used to analysis. Independent associations were considered with $p<0.05$.
\end{abstract}

Result: Among the 421 participants enrolled, 292 (69.4\%) were adult and $129(30.6 \%)$ were children. More than half $243(57.7 \%)$ of the participants were females. The adult median age at ART initiation was 38.0 years with inter quartile rage (IQR) 10 and for children 9.8 years with IQR 4.The median duration of treatment failure from initiation of treatment was 87 months (IQR 110-65 months). A total of 45 (10.7\%) participants were found to have treatment failure. The median CD4 T-cells at initiation of Anti retroviral therapy were $147 \mathrm{cells} / \mu \mathrm{l}$ (IQR 226-84.5). The median time to detect virological failure was 47 months. Sensitivity of immunologic failure of predicting virological failure was $62.2 \%$. Clinical stage II 374 (88.8\%) was the predominant clinical stage.

Conclusion: The prevalence of treatment failure in this study was $10.7 \%$. Long duration on treatment, conducting faith healing, immunologic failure, high medication dosage, and ambulatory functional status at baseline and not feeling privacy during consultation and counseling were found to be significant predictors of treatment failure. Therefore early identification of associated factors and monitoring treatment failure has to be strengthened to benefit patients from prevent further complication

Keywords: Treatment failure; First line HAART; HIV/AIDS; Bahir Dar

\section{Background}

Human immunodeficiency virus (HIV) is responsible for a worldwide pandemic, and it is the cause of acquired immune deficiency syndrome (AIDS). According to UNAIDS report 2017 on the Global AIDS Epidemic in 2016, there were 36.7million (30.8 million-42.9 million) people living with HIV. In addition, 1.8 million (1.6 million-2.1 million) people became newly infected with HIV and 1.0million (830 000-1.2 million) people died from AIDS-related illnesses in the same year [1].

Globally HIV estimated among children (15 years) living with HIV 2.1 million (1.7 million-2.6 million), New HIV infections in 160000 (100 000-220 000) and AIDS-related deaths in 120000 (79 000-160 000) [1].

Global scale-up of antiretroviral therapy has been the primary contributor to a $48 \%$ declinein deaths from AIDS-related causes, from a peak of 1.9 million ( 1.7 million-2.2 million) in 2005 to 1.0 million (830 000-1 2 million) in 2016. Despite the fact that 51\%of people living with
HIV globally are female, higher treatment coverage and betteradherence to treatment among women have driven more rapid declines in AIDSrelated deaths among females: deaths from AIDS-related illnesses were $27 \%$ lower among womenand girls in 2016 than they were among men and boys. Nonetheless, AIDS related illnesses remain the leading cause of death among women of reproductive age (15-49 years) globally, and

*Corresponding author: Bokretsion Gidey, M.Sc., Malaria and Other Neglected Tropical Disease Research Team, Bacterial, Parasitic and Zoonotic Diseases Research Directorate, Ethiopian Public Health Institute (EPHI), P.O.box-1242, Addis Ababa, Ethiopia, Tel: +251931571838; E-mail: bokregidey@yahoo.com

Received October 30, 2017; Accepted November 10, 2017; Published November 17, 2017

Citation: Brhane BG, Nibret E, Abay GK (2017) HIVIAIDS Treatment Failure and its Determinant Factors among First Line HAART Patients at Felege-Hiwot Referra Hospital, Bahir Dar, Northwest Ethiopia. J AIDS Clin Res 8: 744 doi: 10.4172/21556113.1000744

Copyright: (c) 2017 Brhane BG, et al. This is an open-access article distributed under the terms of the Creative Commons Attribution License, which permits unrestricted use, distribution, and reproduction in any medium, provided the original author and source are credited. 
they are the second leading cause of death for young women aged 15-24 years in Africa [2].

Although there is no curative therapy for HIV/AIDS, the advent of highly active antiretroviral therapy (HAART) played a critical role in the clinical management of HIV infected individuals by restoring the immune function, preventing morbidity and mortality, improving quality of life, and preventing the transmission of the virus to other uninfected individuals [3].

As of December 2011, over 8 million people infected with HIV were receiving antiretroviral therapy (ART) in low- and middle income countries which represents a 26-fold increase since 2005 [4]. Due to HIV's error-prone replication, high mutation rate and viral recombination, development of some HIV drug resistance (HIVDR) is inevitable, even with appropriate ART prescribing and adherence [58]. HIVDR has significant human and financial implications: it limits treatment options. Moreover, the second-line ART regimens involve more long-term toxicity and 4 to 8 times annual cost compared to firstline regimens [9]. As the number of people on treatment increases, the emergence of meaningful population-level HIVDR becomes a greater risk which has the potential to undermine the dramatic gains that ART programs have had in reducing the morbidity and mortality of HIVinfected people in resource-limited settings [10].

Moreover, the limited access of pediatric regimens, the challenges of pediatric ART adherence and the likelihood of HIV drug resistance development raise great public health concern about treatment failure and drug resistance in children and even in adults receiving ART [11].

In Ethiopia, ART service began in August 2003 with payment and free ART was launched in January 2005 [12]. Studies in East Africa have shown a high prevalence of immunologic failure ranging from $8 \%$ to $38 \%$ among clients on first-line HAART, and furthermore, the magnitude increases as the time of follow-up increases [13-15]. In 2016 in Ethiopia around 710,000 peoples $(570,000-880,000)$ are found living with HIV from which nearly half 420,000 people get ART treatment [1].

The immunological failure rate in Ethiopia a study conducted in Deberemarkos Hospital was found to be high [14]. Conversely, the virologic failure rate conducted in Gondar University Hospital showed that $4.1 \%$ was found to be low [16]. The timing and accuracy of identifying treatment failure in resource-limited settings are fundamental but challenging [17].

Monitoring of ART program factors known to be associated with the emergence of treatment failure for the purpose of improving programmatic functioning, may minimize the emergence of preventable HIVDR, especially at ART sites where viral load is not routinely available $[6,8,18,19]$. Inappropriate prescribing, treatment interruptions due to suboptimal patient adherence, poor patient retention on ART, or late initiation or when stock-outs occur. These factors have been shown to be associated with the development of HIV treatment failure $[6,8,20]$.

Moreover, there is a need of national baseline data on the level of treatment failure which will aid the third target of 90-90-90 ambitious plan to help end the AIDS epidemic by 2020 [1] to assist on the national treatment program by providing objective evidence. Moreover; there is a limited data regarding the treatment failure and factors increasing the treatment failure in first line HAART and in consequence, early and/or lately switch to second-line HAART can happen with the high expense of the drug and toxic increments and more to uncontrolled drug resistance. Therefore, this study assessed the prevalence of HIV/AIDS treatment failure and its determinant factors among first-line HAART patients in Felegehiwot Referral Hospital, Bahir Dar, Northwest Ethiopia.

\section{Materials and Methods}

\section{Study area and period}

This study was conducted at Felegehiwot Referral Hospital in Bahir Dar town, northwest Ethiopia and data collection period was from August 01 to September 30, 2016

\section{Study design}

Hospital-based cross-sectional study was conducted to evaluate HIV/AIDS treatment failure and its determinant Factors.

\section{Source population}

All HIV/AIDS patients who were enrolled at first line HAART follow up in Felegehiwot Referral Hospital.

\section{Study population}

All HIV/AIDS patients who were enrolled in HAART program, who met the inclusion criteria and present during the study period to get service from ART unit.

\section{Inclusion and exclusion criteria}

Inclusion criteria:

- All in first line HAART patients and had follow up at least six months.

\section{Exclusion criteria:}

- Patients on second line treatment.

- Acute Febrile Illness (AFIs).

\section{Sampling technique and sample size}

The sample size was determined based on single population formula with the following assumption. $n=z^{2} p(1-p) / w 2 ~[21,22] n=$ minimum sample size, $\mathrm{W}=$ estimated error $=0.05 ; \mathrm{P}=$ population proportion in problem (estimated prevalence) $=0.5$, and $\mathrm{Z} \alpha / 2=1.96$ by assuming $95 \%$ confidence interval. The minimum sample size was $\mathrm{n}=384$ (by adding $10 \%$ non-response rate) 421 participants participated. Systematic random sampling technique was used to select 421 participants from ART to follow up.

\section{Socio-demographic and determinant factors assessment}

Data were collected from patients' card starting from ART commencement (baseline data and other information) and face to face interview using structured questionnaire. The questionnaire was developed based on the review of different kinds of literature related to the determinant factors. The questionnaire was translated from English to Amharic language and finally to English.

\section{Specimen collection and laboratory investigation}

After the study participants had been asked for their consent to be interviewed and to give sample blood, about $5 \mathrm{~mL}$ venous blood was withdrawn $(50 \mu \mathrm{l}$ for a CD4 count and centrifuged plasma for HIV viral load determination) from each study participants. The sample was collected by qualified health care professionals for the immediate laboratory analysis of the blood sample and to separate the plasma. Some anthropometric indicators were also assessed and measured side by side as well. Analysis of viral load and CD4 counts parameters were conducted based on standard procedure. 


\section{Determination of CD4 counts}

To determine CD4+ T cells and CD4\%, fifty micro litters of fresh whole blood was added to single reagent tube and processed according to the protocol set by Becton Dickinson Biosciences (BD, San Jose, California, USA).

\section{Determination of viral load}

The whole blood containing EDTA anticoagulant was allowed to settle for 15 to $30 \mathrm{~min}$ and, then centrifuged at $3000-4000 \mathrm{rpm}$ for $5 \mathrm{~min}$ and the plasma was separated from the cell within $6 \mathrm{~h}$ and stored at $-20^{\circ} \mathrm{C}$ if the analysis was delayed. The sample was processed according to the procedure using a quantitative real-time HIV-1 assay (by m2000sp and m2000rt Abbott). The instrument was set to aspirate $200 \mu \mathrm{l}$ of plasma and the lower detection limit based on the sample volume was 40 copies $/ \mathrm{ml}$.

\section{Data quality}

The validity of the questionnaires was assured by proper designing and also pre-testing the questionnaire in $5 \%$ of respondents other than those involved in the actual study. Before commencing the actual data collection, training was given to the data collectors. Questionnaires were reviewed and checked by the supervisors and principal investigators. The necessary feedback was offered to data collectors in the next morning.

\section{Data processing and analysis}

\section{Variables of the study:}

- Dependent variable: Treatment failure/virologic failure.

- Independent variables: Patient medication Adherence, Sociodemographic variables (age, sex, marital status, occupational, and educational status), WHO clinical stages, CD4 count (baseline, current), ART regimen, Income, Change/substitute of treatment, Detection of tuberculosis during the course of therapy and Alcohol usage were assessed. Moreover, knowledge and perception on HIV and ART (knowledge and information on ART, Perception of treatment) service delivery environment distance from home to the clinic, quality of care, trust in health care (private consultancy) providers, pill burden concerns.

Data analysis: The data were cleaned, checked for completeness and entered in to EPI info version 3.5.1 and compiled and analyzed using SPSS packages version 20. Descriptive statistics, odds ratio (both crude odds ratio and adjusted odds ratio), Sensitivity, specificity, Positive predictive value, Negative predictive value, life table and ROC curves were used in the analysis. Percentage, means, medians, standard deviations and ranges were used to describe findings. The data were also analyzed using univariate and multivariate logistic regression and to determine the effect of various factors on virologic failure.

The cumulative prevalence of first-line ART failure was ascertained from the proportion of participants with viral load $\geq 1000$ copies $/ \mathrm{ml}$ at one point for virologic failure. Similarly, immunologic and clinical treatment failures were defined according to WHO (WHO, 2013); CD4+ T cell count below the baseline or persistent CD4+ T-cell levels below 100 cells $/ \mathrm{mm}^{3}$ for immunologic failure. Logistic regression analysis was done to determine the extent to which the risk factors are associated with HAART treatment failure. All socio demographic and clinical characteristics (variables) were subjected to uni-variate analysis for calculating Crude Odds Ratio (COR). To identify the independent explanatory variable (s) of the dependent variable, factors with $\mathrm{p}<0.25$ at univariate analysis were selected and included in multivariate analysis. The model was then built by dropping the most insignificant factor one at a time in step-wise manner and the factor (s) that appeared in the final model with $\mathrm{p}<0.05$ was taken to be the factor (s) that independently associated with treatment failure.

\section{Ethical consideration}

Ethical clearance was obtained from Bahir Dar University Ethics Review Committee. Each respondent was informed about the objective of the study and findings of the study for improving health of those attending ART section. Written consent and assent were obtained from each study participant. Involvement in the study was endorsed only after written consent is obtained. Any person who was not willing to participate in the study was not forced to participate. They also informed that all data obtained from study participant kept confidential by using codes instead of any personal identifiers.

\section{Results}

\section{Socio-demographic characteristics}

From a total of 421 study participants, 292 (69.4\%) were adults and $129(30.6 \%)$ were children. The median age of the adult and the children was 38.0 years (IQR-10) and 9.8 years (IQR-4) respectively. Majority of the adult participants 117 (40.1\%) were in 30-40 years and in children $68(16.2 \%)$ were in 11-17 years of age. Seventy three $(56.6 \%)$ of the children were females whereas $170(58.2 \%)$ of the adults were females. Regarding the educational level 95 (32\%) of them completed primary school, $72(24.7 \%)$ completed college or university. Eighty one (27.7\%) of the study participants had monthly income ranging from 37 102 \$ per month. Eighty eight (30.1\%) were governmental employees (Table 1).

\section{Baseline clinical and immunologic characteristics}

The median CD4 count at ART initiation was 147 cell/ $\mu$ l (IQR 22684.5). Majority of study participants, 284 (67.5\%) had suffered WHO stages 3 and 4 conditions at the time of ART initiation. The proportion of patients who commenced ART after developing signs or symptoms suggestive of mild immunosuppression (WHO stage 2) was seen among $81(19.2 \%)$ and WHO clinical stage one among 156 (13.3\%). During HAART commencement, 316 (75.1\%) were working by their functional status and TB infection was confirmed in 129 (30.6\%) starting from HAART initiation (Table 2).

\section{Types of ARV first line regimen during initiation}

During treatment initiation, different types of first line ART drugs were used as choice of treatment for HIV/AIDS patients. Having this point, d4T based regimen contained NNRTIs of both NVP (d4T/3TC/ $\mathrm{NVP}$ ) and EFV (d4T/3TC/EFV), 115 (27.3\%) and 30 (7.1\%) respectively Similarly, the AZT based regimen was highest into AZT/3TC/NVP and AZT/3TC/EFV, 68 (42\%) and 54 (12\%) respectively. On the other hand TDF based regimens consisted of TDF/3TC/EFV 58 (13.8\%) and TDF/3TC/NVP 24 (5.7\%). Regarding treatment regimen substitution, only 162 (38.5\%) study participants received a substitution and AZT based substitution was 63 (19.1\%) held the majority one (Table 2).

\section{Prevalence clinical, immunologic and virologic failures}

Clinical failure: WHO clinical stage I and II were the most dominant clinical presentations 374 (88.8\%) participants. Forty seven $(11.2 \%)$ of participants were at stage III. In this study, WHO clinical stage 4 presentations were not observed (Table 3). 


\begin{tabular}{|c|c|c|c|}
\hline & \multirow{2}{*}{$\begin{array}{c}\text { Adults } \\
65(22.5 \%)\end{array}$} & \multirow{2}{*}{ Children } \\
\hline \multirow{4}{*}{$\begin{array}{l}\text { Age } \\
\text { Adults }\end{array}$} & $18-29$ & & \\
\hline & $30-40$ & $117(40.1 \%)$ & \\
\hline & $41-50$ & $80(27.4 \%)$ & \\
\hline & $51-80$ & $30(10.3 \%)$ & \\
\hline \multirow[t]{3}{*}{ Children } & $1-5$ & \multirow{3}{*}{$N / A$} & $29(22.5 \%)$ \\
\hline & $6-10$ & & $32(24.8 \%)$ \\
\hline & $11-17$ & & $68(52.7 \%)$ \\
\hline \multicolumn{2}{|l|}{$\begin{array}{l}\text { Gender } \\
\text { Female } \\
\text { Male }\end{array}$} & $\begin{array}{l}170(58.2 \%) \\
122(41.8 \%)\end{array}$ & $\begin{array}{l}73(56.6 \%) \\
56(43.4 \%)\end{array}$ \\
\hline \multicolumn{2}{|c|}{$\begin{array}{l}\text { Residence } \\
\text { Urban } \\
\text { Rural }\end{array}$} & $\begin{array}{c}273(93.5 \%) \\
19(6.5 \%)\end{array}$ & $\begin{array}{c}118(91.5 \%) \\
11(8.5 \%)\end{array}$ \\
\hline \multicolumn{2}{|c|}{$\begin{array}{l}\text { Marital status } \\
\text { Single } \\
\text { Married } \\
\text { Divorced } \\
\text { Widowed }\end{array}$} & $\begin{array}{c}30(10.3 \%) \\
151(51.7 \%) \\
59(20.2 \%) \\
52(17.8 \%)\end{array}$ & N/A \\
\hline \multicolumn{2}{|c|}{$\begin{array}{l}\text { Educational Status } \\
\text { Not formal/not in school } \\
\text { Primary school } \\
\text { Secondary } \\
\text { Tertiary }\end{array}$} & $\begin{array}{l}62(21.2 \%) \\
95(32.5 \%) \\
63(21.6 \%) \\
72(24.7 \%)\end{array}$ & $\begin{array}{c}34(26.4 \%) \\
80(62 \%) \\
15(11.6 \%) \\
\text { N/A }\end{array}$ \\
\hline \multicolumn{2}{|c|}{$\begin{array}{l}\text { Occupational status (Adults) } \\
\text { Gov. Employee } \\
\text { Merchant } \\
\text { Driver } \\
\text { House wife } \\
\text { Unemployed } \\
\text { Self-employee }\end{array}$} & $\begin{array}{l}88(30.1 \%) \\
47(16.1 \%) \\
8(2.7 \%) \\
35(12 \%) \\
41(14 \%) \\
73(25 \%)\end{array}$ & N/A \\
\hline \multicolumn{2}{|c|}{$\begin{array}{l}\text { Monthly Income* }(\$) \\
\text { Unknown } \\
11-36 \\
37-102 \\
103-159 \\
160-454\end{array}$} & $\begin{array}{l}\text { Participant } \\
79(27.1 \%) \\
53(18.2 \%) \\
81(27.7 \%) \\
46(15.8 \%) \\
33(13.3 \%)\end{array}$ & $\begin{array}{c}\text { Family income } \\
\mathrm{N} / \mathrm{A} \\
18(14 \%) \\
76(58.9 \%) \\
18(14 \%) \\
17(13.1 \%)\end{array}$ \\
\hline
\end{tabular}

NB-'Range According to Ethiopian civil servant monthly salary

Table 1: Distribution of Socio-demographic characteristics of study participants at Felegehiwot Referral Hospital, Bahir Dar, Northwest Ethiopia 2016.

Immunologic failure: Quantitative restoration of CD4+ T cells is one of the principal evidence for immune recovery during HAART. Out of 421 study participants, 67 (15.9\%) encountered immunologic failure in which $40(16.5 \%)$ and $27(15.2 \%)$ were females and males respectively. Over time analysis of immunologic failure has shown that $28(42.8 \%)$ study participants encountered immunological failure within 6-48 months (Table 3).

Virologic failure: From the total 421 study participants in first line HAART regimen, prevalence of virologic failure ( $\geq 1000$ RNA copies per $\mathrm{ml}$ ) was found in $45(10.7 \%)$ participants of which $26(10.7 \%)$ and $19(10.7 \%)$ females and males respectively. Since the start of HAART, $23(51.1 \%)$ of them encountered virological failure within 6-48 months. Viral suppression was found among $357(84.8 \%)$ of the participants (Table 3).

Treatment failure: For detecting treatment failure in HAART, monitoring of clinical, immunologic and virologic failures is very important. In general from this study the prevalence of treatment failures were $45(10.7 \%), 67(15.9 \%)$, and $47(11.2 \%)$ of them encountered virologic failure, immunologic failure, and clinical failure respectively. The median month of on HAART was 87 months (IQR-110-65 months). The median time from HAART initiation to

\begin{tabular}{|c|c|c|}
\hline Variables & Category & Frequency $(\%)$ \\
\hline \multirow{6}{*}{ Baseline first line HAART regimen } & D4T/3TC/NVP & $115(27.3 \%)$ \\
\hline & D4T/3TC/EFV & $30(7.1 \%)$ \\
\hline & AZT/3TC/NVP & $140(33.3)$ \\
\hline & AZT/3TC/EFV & $54(12.8 \%)$ \\
\hline & TDF/3TC/NVP & $58(13.8 \%)$ \\
\hline & TDF/3TC/EFV & $24(5.7 \%)$ \\
\hline & D4T/3TC/NVP & $4(2.5 \%)$ \\
\hline & D4T/3TC/EFV & $16(9.9 \%)$ \\
\hline & AZT/3TC/NVP & $68(42.0 \%)$ \\
\hline & AZT/3TC/EFV & $38(23.4 \%)$ \\
\hline \multirow[t]{3}{*}{ First line HAART substitution } & TDF/3TC/NVP & $15(9.2 \%)$ \\
\hline & TDF/3TC/EFV & $21(13.0 \%)$ \\
\hline & Total & $162(100 \%)$ \\
\hline \multirow[t]{4}{*}{ Baseline CD4 results } & $\leq 100$ & $112(26.6 \%)$ \\
\hline & $101-350$ & $216(51.3 \%)$ \\
\hline & $351-500$ & $40(9.5 \%)$ \\
\hline & $\geq 501$ & $53(12.6)$ \\
\hline \multirow[t]{4}{*}{ Baseline WHO stages } & I & $56(13.3 \%)$ \\
\hline & II & $81(19.2 \%)$ \\
\hline & III & $237(56.3 \%)$ \\
\hline & IV & $47(11.2 \%)$ \\
\hline \multirow[t]{2}{*}{ Baseline patient functional status } & Ambulatory & $105(24.9 \%)$ \\
\hline & Working & $316(75.1 \%)$ \\
\hline \multirow[t]{2}{*}{ TB history } & Yes & $129(30.6 \%)$ \\
\hline & No & $292(69.4 \%)$ \\
\hline
\end{tabular}

Table 2: Baseline clinical and immunologic characteristic of study participants at Felegehiwot Referral Hospital Bahir Dar, Northwest Ethiopia $2016(\mathrm{~N}=421)$.

\begin{tabular}{|c|c|c|}
\hline Variable & Categories & Frequency $(\%)$ \\
\hline \multirow[t]{2}{*}{ Presence of treatment failure } & Yes & $84(20 \%)$ \\
\hline & No & $337(80)$ \\
\hline \multirow[t]{2}{*}{ Clinical failure (WHO stages) } & Yes & $47(11.2 \%)$ \\
\hline & No & $374(88.8 \%)$ \\
\hline \multirow[t]{2}{*}{ Immunologic failure } & Yes & $67(15.9 \%)$ \\
\hline & No & $354(84.1 \%)$ \\
\hline \multirow[t]{2}{*}{ Virologic failure } & Yes & $45(10.7 \%)$ \\
\hline & No & $376(89.3 \%)$ \\
\hline \multirow[t]{2}{*}{ Treatment failure regimen backbone } & AZT/3TC & $25(55.6 \%)$ \\
\hline & TDF/3TC & $20(44.4 \%)$ \\
\hline \multirow[t]{3}{*}{ Months from ART initiation } & $6-48$ & $23(51.1 \%)$ \\
\hline & $49-72$ & $8(17.8 \%)$ \\
\hline & $73-158$ & $14(31.1 \%)$ \\
\hline \multirow[t]{6}{*}{ First line HAART regimen } & D4T/3TC/NVP & $12(2.8 \%)$ \\
\hline & D4T/3TC/EFV & $10(2.4 \%)$ \\
\hline & AZT/3TC/NVP & $170(40.3 \%)$ \\
\hline & AZT/3TC/EFV & $91(21.6 \%)$ \\
\hline & TDF/3TC/NVP & $79(18.9 \%)$ \\
\hline & TDF/3TC/EFV & $59(14.0 \%)$ \\
\hline Viral suppression & $\begin{array}{l}\text { Yes } \\
\text { No }\end{array}$ & $\begin{array}{c}357(84.8 \%) \\
64(15.2 \%)\end{array}$ \\
\hline
\end{tabular}

Table 3: Treatment failure after initiation of HAART in HIVIAIDS patients in Felege hiwot Referral Hospital, Bahir Dar, Northwest Ethiopia 2016 (N=421). 
treatment failure was 47 months for virologic failure and 63 months for immunologic failure. From the total participants, 261 (62.0\%) were under AZT based regimen while 138 (32.8\%) were under TDF based regimen and rest $22(5.2 \%)$ were under D4T based regimen. Moreover, the backbone of treatments which showed treatment failure of AZT/3CT/NVP and AZT/3CT/EFV was $25(55.6 \%)$ and TDF/3CT/ NVP 20 (44.4\%) (Table 3).

Performance characteristics of clinical and immunologic failures in prediction of virologic failure: In this study, by ROC curve analysis the area under the curve (AUC) was 0.759 (95\% CI: 0.672 0.847). Immunologic failure had fair predictive values to virologic failure. When immunologic failure compared to the golden standard, virologic failure Sensitivity was $62.2 \%$, specificity $89.6 \%$, PPV $41.8 \%$ and NPV 95.2\% (Table 4).

ROC curve analysis of clinical failure showed that the area under the curve was 0.484 (95\% CI: 0.393-0.576). The area indicated that clinical failure was less predictive of the occurrence of virologic failure. The performance of clinical failure to identify treatment failure, sensitivity was $17.8 \%$, specificity $89.3 \%$, positive predictive value $(17.0 \%)$ and negative predictive value (90.1\%) (Table 4).

Determinant factors of HIV/AIDS treatment failure among patients on first line HAART Bi-variate logistic regression analysis: Using bi-variate logistic regression, association was assessed between age, gender, Residence educational status, income, medication dosage, distance, consultation privacy, faith heal, drug adherence, WHO stage baseline, TB history, CD4 baseline, immunologic failure, duration of treatment, baseline patient functional status, regimen substitutes, baseline regimen, $1^{\text {st }}$ line current regimen with virological failure at various intervals (Table 5).

The bi-variate associations were observed without controlling the effect of other confounding factors it is very difficult to conclude whether the observed statistically significant association with existing causal relationship between the given independent variables and the treatment failure.

Multiple logistic regression analyses: Tables 6 and 7 indicate that taking treatment for long duration, immunologic failure, baseline patient functional status, medication dosage, consultation privacy, conducting faith heal and adherence to ART were found statistically significant association with treatment failure. However; educational status, distance from home to clinic, TB history, CD4 baseline, regimen substitutes, gender, agewere not statistically significant associated with dependent variable.

According to WHO Adherence was defined as optimal and suboptimal (based on pill count and self-report at each visit) when it was $\geq 95 \%$ and $<95 \%$ respectively. Sub-optimal drug adherence $(<95 \%)$ was independent associated risk factor of treatment failure as patients with sub-optimal adherence patients (adjusted odds ratio=9.553, 95\% CI: (3.488-26.164)). Similarly patients who conducted faith healing (adjusted odds ratio=8.124, 95\% CI: 3.075-21-465) associated with higher risk of treatment failure (Table 7).

\begin{tabular}{|l|c|c|c|c|}
\hline Criteria & Sensitivity (\%) & Specificity (\%) & PPV (\%) & NPV (\%) \\
\hline Clinical failure & 17.8 & 89.3 & 17.0 & 90.1 \\
\hline Immunologic failure & 62.2 & 89.6 & 41.8 & 95.2 \\
\hline
\end{tabular}

Table 4: Performance characteristics of clinical and immunologic failures in predicting virologic failure at Felegehiwot Referral Hospital, Bahir Dar, Northwest Ethiopia 2016.

\begin{tabular}{|c|c|c|c|c|c|}
\hline Variables & Categories & All $(n=421)$ & $\begin{array}{c}\text { VF } \\
(n=45)\end{array}$ & $\begin{array}{c}\text { Odds Ratio (OR, } \\
95 \% \mathrm{Cl})\end{array}$ & P-value \\
\hline \multirow[t]{2}{*}{ Gender } & Female & 243 & 26 & 1 & 1 \\
\hline & Male & 178 & 19 & $0.998(0.536-1.875)$ & 0.993 \\
\hline \multirow[t]{2}{*}{ Age group } & Children & 129 & 16 & $0.779(0.407-1.49)$ & 0.450 \\
\hline & Adult & 292 & 29 & 1 & 1 \\
\hline \multirow[t]{2}{*}{ Residence } & Urban & 391 & 43 & 1 & 1 \\
\hline & Rural & 30 & 2 & $1.730(0.399-7.517)$ & 0.465 \\
\hline \multirow[t]{4}{*}{$\begin{array}{l}\text { Educational } \\
\text { status }\end{array}$} & $\begin{array}{l}\text { No formal } \\
\text { education }\end{array}$ & 96 & 15 & $0.491(0.18-1.336)$ & 0.164 \\
\hline & primary & 175 & 20 & $0.705(0.271-1.834)$ & 0.473 \\
\hline & secondary & 78 & 4 & $1.682(0.455-6.22)$ & 0.436 \\
\hline & Tertiary & 72 & 6 & 1 & 1 \\
\hline \multirow{2}{*}{$\begin{array}{l}\text { Distance } \\
\text { from home } \\
\text { to clinic }\end{array}$} & $\leq 10 \mathrm{~km}$ & 248 & 30 & 1 & 1 \\
\hline & $>10 \mathrm{~km}$ & 173 & 15 & $1.450(0.755-2.784)$ & 0.265 \\
\hline \multirow{2}{*}{$\begin{array}{l}\text { consultation } \\
\text { of privacy }\end{array}$} & Yes & 399 & 34 & 1 & 1 \\
\hline & No & 22 & 11 & $6.435(2.81-14.73)$ & $0.000^{*}$ \\
\hline \multirow{2}{*}{$\begin{array}{l}\text { Faith healing } \\
\text { medicine }\end{array}$} & Yes & 94 & 27 & $7.045(3.67-13.54)$ & $0.000^{*}$ \\
\hline & No & 327 & 18 & 1 & 1 \\
\hline \multirow{2}{*}{$\begin{array}{l}\text { CD4 value } \\
\text { baseline }\end{array}$} & $\leq 100$ & 112 & 22 & $3.04(1.61-5.711)$ & $0.001^{*}$ \\
\hline & $>100$ & 309 & 23 & 1 & 1 \\
\hline \multirow{3}{*}{$\begin{array}{l}\text { Duration } \\
\text { of ART } \\
\text { treatment }\end{array}$} & $6-48$ & 105 & 23 & 1 & 1 \\
\hline & $49-72$ & 70 & 8 & $2.174(0.911-5.186)$ & 0.080 \\
\hline & $73-158$ & 246 & 14 & $4.648(2.284-9.459)$ & $0.001^{*}$ \\
\hline \multirow{2}{*}{$\begin{array}{l}\text { Drug } \\
\text { adherence }\end{array}$} & $<95$ & 74 & 25 & $8.342(4.311-16.143)$ & $0.001^{*}$ \\
\hline & $\geq 95$ & 347 & 20 & 1 & 1 \\
\hline \multirow{2}{*}{$\begin{array}{l}\text { Drug } \\
\text { substitutes }\end{array}$} & Yes & 157 & 22 & $1.708(0.917-3.178)$ & 0.091 \\
\hline & No & 264 & 23 & 1 & 1 \\
\hline \multirow{2}{*}{$\begin{array}{l}\text { Medication } \\
\text { dosage }\end{array}$} & $1-2$ & 333 & 24 & 1 & 1 \\
\hline & $3-5$ & 88 & 21 & $4.035(2.123-7.672)$ & $0.001^{*}$ \\
\hline \multirow{2}{*}{$\begin{array}{l}\text { Types of } \\
\text { drugs }\end{array}$} & AZT based & 283 & 25 & $1.749(0.934-3.275)$ & 0.081 \\
\hline & TDF based & 138 & 20 & 1 & 1 \\
\hline \multirow{2}{*}{$\begin{array}{l}\text { Functional } \\
\text { status }\end{array}$} & Ambulatory & 105 & 26 & $5.145(2.709-9.771)$ & $0.001^{*}$ \\
\hline & Working & 316 & 19 & 1 & 1 \\
\hline \multirow[t]{2}{*}{ TB ever } & Yes & 129 & 21 & $2.171(1.160-4.064)$ & $0.015^{*}$ \\
\hline & No & 292 & 24 & 1 & 1 \\
\hline \multirow[t]{2}{*}{$\begin{array}{l}\text { Immunologic } \\
\text { failure }\end{array}$} & Yes & 67 & 28 & $\begin{array}{c}14.232(7.154- \\
28.313)\end{array}$ & $0.001^{*}$ \\
\hline & No & 354 & 17 & 1 & 1 \\
\hline
\end{tabular}

Note:* Has significant association.

Abbreviations: ART: Antiretroviral Therapy; COR: Crude Odds Ratio; AOR: Adjusted Odds Ratio; Cl: Confidence Interval; WHO: World Health Organization

Table 5: Bi-variate logistic regression analysis of socio demographic and clinical associated factors with virologic failure at Felegehiwot Referral Hospital, Bahir Dar, Northwest Ethiopia 2016.

Based on WHO criteria, immunologic failure was found to be significant predictor of the presence of treatment failure/virologic failure. Immunologic failure and high pill burden/medication dosage were high risk factor for treatment/virologic failure (adjusted odds ratio $=8.630,95 \%$ CI: 3.321-22.424) and Adjusted odds ratio=3.827, 95\% CI: 1.360-10.773) respectively. And being ambulatory at baseline was found significant risk factor to treatment failure (adjusted odds ratio=2.972, 95\% CI: 1.185-7.455) (Table 7).

\section{Discussion}

The identification and management of first-line ART failure is a key challenge for HIV programs in resource-limited settings. As HAART continues to be scaled up in Ethiopia, with more Primary Health Care (PHC) facilities providing ART services, increasingly more efforts and 
Page 6 of 8

\begin{tabular}{|c|c|c|c|c|c|c|c|}
\hline Variables & Categories & $\underset{\substack{\text { All } \\
(n=421)}}{-}$ & $\underset{(n=45)}{V F}$ & $\begin{array}{c}\text { COR } \\
(95 \% \mathrm{Cl})\end{array}$ & P-value & $\begin{array}{c}\text { AOR } \\
(95 \% \mathrm{Cl})\end{array}$ & P-value \\
\hline \multirow[t]{2}{*}{ Gender } & Female & 243 & 26 & 1 & 1 & 1 & 1 \\
\hline & Male & 178 & 19 & $0.998(0.536-1.875)$ & 0.993 & $1.332(0.504-3.520)$ & 0.563 \\
\hline \multirow[t]{2}{*}{ Age group } & Children & 129 & 16 & $0.779(0.407-1.49)$ & 0.450 & $2.161(0.423-11.031)$ & 0.354 \\
\hline & Adult & 292 & 29 & 1 & 1 & 1 & 1 \\
\hline \multirow[t]{4}{*}{ Educational status } & No formal education & 96 & 15 & $0.491(0.18-1.336)$ & 0.164 & $0.299(0.056-1.594)$ & 0.157 \\
\hline & primary & 175 & 20 & $0.705(0.271-1.834)$ & 0.473 & $0.592(0.141-2.488)$ & 0.474 \\
\hline & secondary & 78 & 4 & $1.682(0.455-6.22)$ & 0.436 & $1.846(0.325-10.473)$ & 0.489 \\
\hline & Tertiary & 72 & 6 & 1 & 1 & 1 & 1 \\
\hline \multirow{2}{*}{$\begin{array}{l}\text { Consultation of } \\
\text { privacy }\end{array}$} & Yes & 399 & 34 & 1 & 1 & 1 & 1 \\
\hline & No & 22 & 11 & $6.435(2.81-14.73)$ & 0.001 & $4.865(1.499-15.792)$ & $0.008^{*}$ \\
\hline \multirow[t]{2}{*}{ Functional status } & Ambulatory & 105 & 26 & $3.190(1.246-8.165)$ & 0.001 & $2.972(1.185-7.455)$ & $0.020^{*}$ \\
\hline & Working & 316 & 19 & 1 & 1 & 1 & 1 \\
\hline
\end{tabular}

Note:* Has significant association.

Abbreviations: ART: Antiretroviral Therapy; COR: Crude Odds Ratio; AOR: Adjusted Odds Ratio; Cl: Confidence Interval; WHO: World Health Organization

Table 6: Multiple logistic regression analysis of socio demographic associated factors with virological failure in Felegehiwot Referral Hospital Bahir Dar, Northwest Ethiopia 2016 .

\begin{tabular}{|c|c|c|c|c|c|c|c|}
\hline Variables & Categories & All $(n=421)$ & $\begin{array}{c}\text { VF } \\
(n=45)\end{array}$ & $\begin{array}{c}\text { COR } \\
(95 \% \mathrm{Cl})\end{array}$ & P-value & $\begin{array}{c}\text { AOR } \\
(95 \% \mathrm{Cl})\end{array}$ & P-value \\
\hline \multirow[t]{2}{*}{ CD4 value baseline } & $\leq 100$ & 112 & 22 & $3.04(1.61-5.711)$ & 0.001 & $0.514(0.127-2.080)$ & 0.351 \\
\hline & $>100$ & 309 & 23 & 1 & 1 & 1 & 1 \\
\hline \multirow[t]{3}{*}{ Duration of ART treatment } & $6-48$ & 105 & 23 & 1 & 1 & 1 & 1 \\
\hline & $49-72$ & 70 & 8 & $2.174(0.911-5.186)$ & 0.080 & $2.240(0.597-8.402)$ & 0.101 \\
\hline & $73-158$ & 246 & 14 & $4.648(2.284-9.459)$ & 0.001 & $5.797(1.661-20.232)$ & $0.006^{*}$ \\
\hline \multirow[t]{2}{*}{ Faith heal medicine } & Yes & 94 & 27 & $7.045(3.67-13.54)$ & 0.001 & $8.124(3.075-21-465)$ & $0.001^{*}$ \\
\hline & No & 327 & 18 & 1 & 1 & 1 & 1 \\
\hline \multirow{2}{*}{$\begin{array}{l}\text { Drug adherence } \\
\text { (WHO) }\end{array}$} & $<95$ & 74 & 25 & $8.342(4.311-16.143)$ & 0.001 & $9.553(3.488-26.164)$ & $0.001^{*}$ \\
\hline & $\geq 95$ & 347 & 20 & 1 & 1 & 1 & 1 \\
\hline \multirow[t]{2}{*}{ ARV regimen substitutes } & Yes & 157 & 22 & $1.708(0.917-3.178)$ & 0.091 & $0.548(0.193-1.566)$ & 0.259 \\
\hline & No & 264 & 23 & 1 & 1 & 1 & 1 \\
\hline \multirow[t]{2}{*}{ Medication dosage } & $1-2$ & 333 & 24 & 1 & 1 & 1 & 1 \\
\hline & $3-5$ & 88 & 21 & $4.035(2.123-7.672)$ & 0.001 & $3.827(1.360-10.773)$ & $0.016^{*}$ \\
\hline \multirow[t]{2}{*}{ TB ever } & Yes & 129 & 21 & $2.171(1.160-4.064))$ & 0.015 & $1.697(0.601-4.786)$ & 0.318 \\
\hline & No & 292 & 24 & 1 & 1 & 1 & 1 \\
\hline \multirow[t]{2}{*}{ Immunologic failure } & Yes & 67 & 28 & $14.232(7.154-28.313)$ & 0.001 & $8.630(3.321-22.424)$ & $0.001^{*}$ \\
\hline & No & 354 & 17 & 1 & 1 & 1 & 1 \\
\hline
\end{tabular}

Note:* Has significant association

Abbreviations: ART: Antiretroviral Therapy; COR: Crude Odds Ratio; AOR: Adjusted Odds Ratio; Cl: Confidence Interval; WHO: World Health Organization

Table 7: Multiple logistic regression analysis of clinical associated factors of virological failure in Felegehiwot Referral Hospital Bahir Dar, Northwest Ethiopia 2016.

resources need to be directed at ensuring that patients who continue to enroll at these facilities receive quality care to optimize their health. This study particularly was designed to identify treatment outcomes, mainly virologic failure and factors associated with it.

Virologic failure is a golden standard for detecting treatment failure in HAART. Prevalence of treatment failure was $10.7 \%(45 / 421)$ among the study participants. This finding was comparable with study conducted in Uganda 9.9\% [23] and Gondar 4.1\% [16]. However; when compared with other studies, for instance a study conducted in Cameron (23.2\%) [24] and costal Kenya (24\%) [18] our finding was very low. The probable variation might be due to study design difference and sample size.

In treatment failure, viral load criteria identified failure significantly earlier (median, 47.0 months; $\mathrm{p}<0.001$ ) than did CD4 count criteria (median, 63.0 months). This study indicated that median time was higher when compared with the study conducted in South Africa 15 months [25], 24 months from Cameroon [24], 24 months from Gondar, Ethiopia [26] and 19.7 months from Addis Ababa, Ethiopia [27].

In this study, as duration on HAART increased, drug failure increased especially in long duration of 73-158 months treatment. Our finding was in line with study conducted in Cameron [28] and in Gondar, Ethiopia [26] showed long time duration of treatment to be one of determinant factors for treatment failure.

By ROC curve analysis, performance of immunologic failure was evaluated against virologic failure. Accordingly the result was sensitivity $62.2 \%$, specificity $89.6 \%$, and positive predictive value $41.8 \%$ and negative predictive value $95.2 \%$ found. These values were higher than study conducted in Uganda [23] 23\%, 90\%,21\% and 91\% sensitivity, specificity, positive predictive value, and negative predictive value respectively and in Tanzania [29] 34\%,94\%,75\% and 71\% sensitivity, specificity, positive predictive value, and negative predictive value respectively. Reason for variation might be due to majority of the study subjects had good adherence. 
Using multivariate logistic regression, there was an association between treatment failure and the following factors: long duration of treatment (73-158 months, $\mathrm{p}<0.05)$, immunologic failure, baseline functional status, high medication dosage, not feeling privacy during consultation, faith heals and sub-optimal adherence to ART during study period. However, there was no statistical significant association ( $p>0.05)$ between treatment failure and the following factors: educational status, distance to clinic, TB history, CD4 baseline, base line regimen, and regimen substitutes.

In this study long time on first line HAART treatment (adjusted odds ratio $=5.797,95 \% \mathrm{CI}$ : $1.661-20.232$ ) were 5.79 times more likely to have treatment failure when compared to patients with short duration on treatment (6-48 months). This finding was in line with study conducted in Gondar [26] and Debrebirhan [5,30].

Poor patient treatment follow up may lead to poor drug adherence by patients may lead to treatment failure. In this study found that suboptimal drug adherence 9 times more risk of developing treatment failure than optimal adherence. This finding was concordant with study conducted in Kenya [18], South Africa [25] and In Gondar, Ethiopia [26].

This study indicated that those who use faith heal/Holy Water 8.12 times more risk to developing treatment failure than not use faith heals. This fining was parallel with study conducted in Ethiopian journal [31] and Debrebirhan, Ethiopia [5,31].

This study found that the patients with an initial ambulatory/ bedridden have 3 times more risk of developing treatment failure than the patients with who had working functional status. This finding with in line with study conducted in Addis Ababa, Ethiopia [32].Also high medication dosage taken by patients indicated that (adjusted odd ration3.827,95\% confidence interval 1.360-10.773) is a significant predictor of treatment failure. Our finding was supported by study conducted in clinical infectious disease [33].

\section{Limitation}

Viral load was done only once due to budget constraint so, there may be missed classification of HIV treatment failure. Acquired drug resistance was not done due to the lack of reagents and available instruments. Being a single-centered study, the result may not also be generalized to all hospitals.

\section{Conclusion}

The prevalence of treatment failure in this study was $10.7 \%$. Long duration on treatment, conducting faith healing, immunologic failure, high medication dosage, and ambulatory functional status at baseline and not feeling privacy during consultation and counseling were found to be significant predictors of treatment failure. Therefore early identification of associated factors and monitoring treatment failure has to be strengthened to benefit patients from prevent further complication.

\section{Recommendations}

Based on the findings of the present study, the following are recommended.

- In resource poor settings, CD4 counting is acceptable and affordable and it should be supportive and be conducted in parallel with viral load testing.

- Duration of time on first line HAART should be checked frequently to protect unnecessary drugs (failed treatment)
- Adherence and other risk factors should be monitored regularly

- Avoiding delays in ART initiation, reinforcing adherence interventions, developing and widely implementing affordable HIV1 RNA monitoring is important.

\section{Author's Contribution}

Author BG participated in the conception, design of the study, coordinated the data collection and analysis, and also prepared the manuscript for publication. Author EN prepared the proposal and involved in data analysis. Author GK determined the CD4 and serum HIV viral load.

\section{Acknowledgement}

We thank the Bahir Dar University, Department of Biology and Ethiopian Public Health institute for providing us laboratory materials and reagents used to collect specimens from patients. We would like to thank to Felege Hiwot ART and Laboratory staffs for the support and work during specimen collection. We would like to express our deepest gratitude to Amhara public health institute for giving us the opportunity to conduct CD4 count and plasma HIV viral load. Our special thanks go to all patients involved in this study for their willingness to participate.

\section{References}

1. UNAIDS, WHO (2017) Global update on HIV treatment. WHO.

2. UNAIDS (2017) Global AIDS monitoring 2017: Indicators for monitoring the 2016 United Nations Political Declaration on HIV and AIDS. UNAIDS, Geneva.

3. Madec Y, Leroy S, Rey-Cuille MA, Huber F, Calmy A (2013) Persistent difficulties in switching to second-line ART in sub-saharan Africa: A systematic review and meta-analysis. PLoS One 8: e82724.

4. Hong S, Jerger L, Badi A, Cohen S, Nachega J, et al. (2013) Medication possession ratio associated with short-term virologic response in individuals initiating antiretroviral therapy in Namibia. PLoS One 8: e56307.

5. Kebede A, Wabe NT (2012) Medication adherence and its determinants among patients on concomitant tuberculosis and antiretroviral therapy in South west ethiopia. N Am J Med Sci 4: 67-71.

6. Kassa D, Gebremichael G, Alemayehu Y, Wolday D, Messele T, et al. (2013) Virologic and immunologic outcome of HAART in Human Immunodeficiency Virus (HIV)-1 infected patients with and without tuberculosis (TB) and latent TB infection (LTBI) in Addis Ababa, Ethiopia. AIDS Res Ther 10: 18.

7. WHO (2013) Consolidated guidelines on the use of antiretroviral drugs for treating and preventing HIV infection: Recommendations for a public health approach. WHO Guidelines 272.

8. Lindsey JC, Hughes MD, Violari A, Eshleman SH, Abrams EJ, et al. (2014) Predictors of virologic and clinical response to nevirapine versus lopinavir/ ritonavir-based antiretroviral therapy in young children with and without prior nevirapine exposure for the prevention of mother-to-child HIV transmission. Pediatr Infect Dis J 33: 846-854.

9. Mata-Marín JA, Garcia GH, Dominguez-Hermosillo JC, Chavez-Garcia M, Banda-Lara Ml, et al. (2015) Effectiveness and risk factors for virological outcome of darunavir-based therapy for treatment-experienced HIV-infected patients. AIDS Res Ther 12: 31

10. Luft LM, Gill MJ, Church DL (2011) HIV-1 viral diversity and its implications for viral load testing: Review of current platforms. Int J Infect Dis 15: e661-670.

11. Mulu A, Maier M, Liebert UG (2015) Low incidence of HIV-1C acquired drug resistance 10 years after roll-out of antiretroviral therapy in Ethiopia: $\mathrm{A}$ prospective cohort study. PLos One 10: e0141318.

12. Shimelis B, Bussa Z, Gebre M, Addisu N (2015) Rationale for changing initia highly active antiretroviral therapy (haart) refimen among hiv/aids patients in west Ethiopia. Int J Life Sci Rev ( IJLSR ) 2: 13-19.

13. Ahoua L, Guenther G, Pinoges L, Anguzu P, Chaix ML, et al. (2009) Risk factors for virological failure and subtherapeutic antiretroviral drug concentrations in HIV-positive adults treated in rural northwesternn Uganda. BMC Infect Dis 9: 81.

14. Melsew YA, Terefe MW, Tessema GA, Ayele TA (2013) Rate of immunological failure and its predictors among patients on highly active antiretroviral therapy at Debremarkos hospital, Northwest Ethiopia: A retrospective follow up study. $\mathrm{J}$ Infect Dis 4: 211 . 
15. Kapesa A, Magesa D, William A, Kaswija J, Seni J, et al. (2014) Determinants of immunological failure among clients on the first line treatment with highly active antiretroviral drugs in Dar es Salaam. Tanzania Asian Pacific Journal of Tropical Biomedicine 4: 620-624.

16. Ayalew MB, Kumilachew D, Belay A, Getu S, Teju D, et al. (2016) First-line antiretroviral treatment failure and associated factors in HIV patients at the University of Gondar Teaching Hospital, Gondar, Northwest Ethiopia. HIV AIDS (Auckl) 8: 141-146.

17. Yirdaw KD, Hattingh S (2015) Prevalence and Predictors of Immunological Failure among HIV Patients on HAART in Southern Ethiopia. PLoS One 10: e0125826.

18. Hassan A, Nabwera H, Mwaringa S, Obonyo C, Sanders E, et al. (2014) HIV1 virologic failure and acquired drug resistance among first-line antiretrovira experienced adults at a rural HIV clinic in coastal Kenya: A cross-sectional study. AIDS Res Ther 11: 9.

19. Wube M, Tesfaye A, Hawaze S (2013) Antiretroviral therapy regimen change among HIVIAIDS patients in nekemt hospital: A primary care hospital in Oromia regional state, Ethiopia. J Appl Pharm Sci 3: 36-40.

20. Jima Y, Angamo M, Wabe N (2013) Causes for antiretroviral regimen change among HIVIAIDS patients in Addis Ababa, Ethiopia. Tanzan J Health Res 15 : $1-9$.

21. Maa Y, Zhaoa D, Yua L, Bulterysb M, Robinsona ML, et al. (2010) Predictors of virologic failure in HIV-1-infected adults receiving first-line antiretroviral therapy in 8 provinces in China. Clin Infect Dis 50: 264-271.

22. Arya R, Antonisamy B, Kumar S (2012) Sample size estimation in prevalence studies. Indian J Pediatr 79: 1482-1488.

23. Reynolds SJ, Nakigozi G, Newell K, Ndyanabo A, Galiwongo R, et al. (2010) Failure of immunologic criteria to appropriately identify antiretroviral treatment failure in Uganda. AIDS 27: 697-700.

24. Meriki HD, Tufon KA, Afegenwi MH, Nyindem B, Atanga PN, et al. (2014)
Immuno-haematologic and virologic responses and predictors of virologic failure in HIV-1 infected adults on first-line antiretroviral therapy in Cameroon. Infect Dis Poverty 3: 5.

25. El-Khatib Z, Katzenstein D, Marrone G, Laher F, Mohapi L, et al. (2011) Adherence to drug-refill is a useful early warning indicator of virologic and immunologic failure among HIV patients on first-line art in South Africa. PLoS One 6: e17518.

26. Zeleke A (2016) Prevalence of antiretroviral treatment failure and associated factors in HIV infected children on antiretroviral therapy at Gondar University Hospital, retrospective cohort study. Int J Med Med Sci 8: 125-132.

27. Bacha T, Tilahun B, Worku A (2012) Predictors of treatment failure and time to detection and switching in HIV-infected Ethiopian children receiving first line anti-retroviral therapy. BMC Infect Dis 12: 197.

28. Zoufaly A, Fillekes Q, Hammel R, Nassimi N, Drexler JF, et al. (2013) Prevalence and determinants of virological failure in HIV-infected children on antiretroviral therapy in rural Cameroon: A cross-sectional study. Antivir Ther 18: 681-690.

29. Mgelea EM, Kisenge R, Aboud S (2014) Detecting virological failure in HIVinfected Tanzanian children. S Afr Med J 104: 696-699.

30. Assefa D, Hussein N (2014) Reasons for regimen change among HIV / AIDS patients initiated on first line highly active antiretroviral therapy in Fitche Hospital, Oromia, Ethiopia. Adv Pharmacol Pharm 2: 77-83.

31. Kloos H, Hailemariam D, Kaba M, Tadele G (2013) Traditional medicine and HIVIAIDS in Ethiopia: Herbal medicine and faith healing. Ethiopian Journa Health Development 27: 141-155.

32. Yimer Y, Yalew A (2015) Magnitude and predictors of Anti-Retroviral Treatment (ART) failure in private health facilities in Addis Ababa, Ethiopia. PLoS One 10 e0126026.

33. Jean-Jacques P, Veronique M, Diane D, Astrid V, Elisabeth B, et al. (2004) Predictors of virologic failure and resistance in HIV-infected patients treated with Nevirapine- or Efavirenz-based antiretroviral therapy. Clin Infect Dis 38: 1311-1316. 